\title{
Assessment of Total Phenolic, Flavonoid Content and Antioxidant Activity of Ocimum sanctum Linn
}

\author{
Ishwor Pathak ${ }^{1^{*}}$, Muna Niraula ${ }^{2}$ \\ ${ }^{1}$ Department of Chemistry, Amrit Campus, Tribhuvan University, Kathmandu, Nepal \\ ${ }^{2}$ Central Department of Chemistry, Tribhuvan University, Kathmandu, Nepal \\ *Corresponding E-mail: pathakishwor14@gmail.com
}

(Received: Sept. 30, 2019; Revised: Dec. 26, 2019 \& Accepted: Dec. 28, 2019)

\begin{abstract}
Ocimum sanctum, commonly known as Tulasi in Nepal, is a pharmacologically important plant due to its active constituents. In this work, extraction was carried out in hexane, chloroform and methanol solvents and their phytochemical screening was performed. Total phenolic and flavonoid contents in the plant were measured by Folin-Ciocalteu colorimetric method and aluminum chloride colorimetric method respectively. Antioxidant activity of the extracts was evaluated using 1,1-diphenyl-2-picrylhydrazyl (DPPH) radical scavenging assay. Alkaloids, flavonoids, tannins, glycosides, polyphenols, terpenoids, tannins and steroids are mainly found in the extracts. Based on the result obtained, the plant posses a significant amount of total phenolic and total flavonoid content. Both phenolic and flavonoid contents were highest in methanol extract, followed by chloroform and hexane extract. Antioxidant activity of the extracts as ascorbic acid standard ( $\mathrm{IC}_{50}$ value $=41.34 \mu \mathrm{g} / \mathrm{mL})$ was in the order of methanol extract $\left(\mathrm{IC}_{50}\right.$ value $\left.=47.73 \mu \mathrm{g} / \mathrm{mL}\right)>$ chloroform extract $\left(\mathrm{IC}_{50}\right.$ value $\left.=79.46 \mu \mathrm{g} / \mathrm{mL}\right)>$ hexane extract $\left(\mathrm{IC}_{50}\right.$ value $\left.=94.68 \mu \mathrm{g} / \mathrm{mL}\right)$. The extent of the antioxidant activity of the plant is following the number of total phenolics and flavonoids present in it.
\end{abstract}

Keywords: Ocimum sanctum, extract, phenolic content, flavonoid content, antioxidant activity

\section{Introduction}

Plants are primary sources of medicines since ancient times. Medicinally important plants contain the various bioactive secondary metabolites having several therapeutics importances [1]. Medicinal plants are advantageous for various treatments due to their fewer side effects, less expensive, efficacy and availability throughout the world. In Ayurveda, Ocimum sanctum Linn. has been used for its healing properties of the mind, body, and spirit [2]. Ocimum sanctum, commonly known as Tulasi or Tulsi in Nepali and Holy Basil in English, is the aromatic plant in the family Liliaceae [3]. It is a branched and erect herb having hair all over [4]. It is the most sacred plant among all the herbs found in Nepal. Different parts of $O$. sanctum (leaves, stems, flowers, roots, seeds and even whole plant) have been used for the treatment of bronchitis, arthritis, malaria, diarrhea, dysentery, skin disease, chronic fever, insect bite etc, [5,6]. Evidence shows that $O$. sanctum cures the physical, chemical, psychological, and metabolic stress of the human body by a unique combination of pharmacological actions [7]. It controls metabolic stress through normalization of blood glucose, blood pressure and lipid levels and psychological stress by enhancing positive effects on memory through anxiolytic and antidepressant properties [8]. O. santcum also possesses anti-infertility, anticancer, antidiabetic, antifungal, antimicrobial, hepatoprotective, antispasmodic, analgesic and cardioprotective properties [9]. The plant is a rich source of essential oil and bioactive phytochemical constituents like alkaloids, flavonoids, terpenoids, phenolics, tannins and saponins $[1,10]$. Polyphenols and flavonoids present in this plant are largely responsible for imparting various therapeutic values including antioxidant potentiality. Antioxidants are the chemical compounds that can scavenge free radicals that are generated in the body due to various reasons. Free radicals are capable of attacking the healthy body cells which may lead to cellular damage, several diseases and disorders [11]. 


\section{Materials and Methods}

\section{Plant materials}

Fresh and matured leaves of Ocimum sanctum were collected from Dhading, Nepal, in the December month of 2018. The plant was authenticated at the Department of Botany, Amrit Campus, Kathmandu, Nepal. The collected leaves were cleaned, shade dried and powdered and stored in airtight bottles.

\section{Extraction}

The dried and powdered leaves of Ocimum sanctum were extracted separately with three different solvents hexane, chloroform and methanol by using soxhlet apparatus. Accurately weighed $50 \mathrm{~g}$ powdered leaves were filled in a thimble and placed in the central assembly of the soxhlet apparatus. Accurately measured $250 \mathrm{~mL}$ solvent such as hexane, chloroform, and methanol was added separately to a $500 \mathrm{~mL}$ round bottom flask. The extraction was done at 68 ${ }^{\circ} \mathrm{C}, 61{ }^{\circ} \mathrm{C}$, and $64{ }^{\circ} \mathrm{C}$ for six hours respectively. After that, the obtained liquid extracts were concentrated using a rotary evaporator (IKA RV 10 digital). The percentage yield $(\mathrm{w} / \mathrm{w})$ of the crude extracts was calculated and stored in the refrigerator at $5{ }^{\circ} \mathrm{C}$ till required for analysis.

\section{Phytochemical screening}

The hexane, chloroform, and methanol extracts (1 gm) were completely dissolved in $100 \mathrm{~mL}$ of their mother solvents for the stock solution preparation. The obtained stock solutions were subjected to phytochemical screening by following standard protocols $[12,13]$.

\section{Determination of total phenolic content}

Total phenolic content was determined by the modified Folin-Ciocalteu colorimetric method based on the oxidation-reduction reaction [14-16]. The stock solutions of hexane, chloroform, and methanol extracts were prepared by dissolving $100 \mathrm{mg}$ in $1 \mathrm{~mL}$ of their mother solvents. Serial dilutions were carried out to get the concentrations of $0.125,0.25,0.5$ and $1.0 \mathrm{mg} / \mathrm{mL}$. $1.0 \mathrm{~mL}$ of each solution was taken in a test tube, and $5 \mathrm{~mL}$ of $10 \%$ Folin-Ciocalteu reagent was added on it. After five minutes, $4 \mathrm{~mL}$ of $7 \%$ $\mathrm{Na}_{2} \mathrm{CO}_{3}$ was added to the mixture. The mixture was shaken well and allowed to incubate for 30 minutes at $40{ }^{\circ} \mathrm{C}$ for blue color development. The absorbance was measured at $760 \mathrm{~nm}$ against blank using a double beam UV/Visible spectrophotometer (UV professional double beam, Shimadzu made). Total phenolic content was determined as $\mathrm{mg} / \mathrm{g}$ of gallic acid equivalent (mg of GAE/g of dry extract) by using the equation obtained from a standard gallic acid calibration curve $\mathrm{y}=0.014 \mathrm{x}, \mathrm{R}^{2}=0.9951$. Values are presented as the mean $\pm \mathrm{SE}$ of each three replicates.

\section{Gallic acid calibration curve}

The Gallic acid calibration curve was prepared by the Folin-Ciocalteu reagent method with modification. Gallic acid $(10 \mathrm{mg})$ was dissolved in methanol $(1 \mathrm{~mL})$. It was a concentration of $10 \mathrm{mg} / \mathrm{mL}$. It was diluted by adding methanol to prepare serial concentrations 10 , 25,50 and $100 \mu \mathrm{g} / \mathrm{mL}$. The above same procedure was followed for gallic acid standard. The absorbance was measured for all standard solutions by using UVspectrophotometer (UV professional double beam, Shimadzu made) at a constant wavelength of $760 \mathrm{~nm}$ [17].

\section{Determination of total flavonoid content}

The total flavonoid content of extracts was estimated by the aluminum chloride colorimetric method by following standard protocol by Hossain et al. and Chandra et al. with some modifications [18-20]. Stock solutions of all three extracts were prepared by dissolving each extract $(100 \mathrm{mg})$ separately with their mother solvents. Serial dilutions were carried out to get the concentrations of $0.125,0.25,0.5$ and $1.0 \mathrm{mg} / \mathrm{mL}$. Different concentrations of different extracts $(1 \mathrm{~mL})$ were taken in different test tubes and added double distilled water $(4.0 \mathrm{~mL})$ and $5 \%$ sodium nitrate $(0.3 \mathrm{~mL})$ then mixed. All the test tubes were kept in a dark place for 6 minutes. Then $10 \%$ aluminum chloride $(0.3 \mathrm{~mL})$ was added into the test tube and wait for $5 \mathrm{~min}$ in the dark for complete reaction. Finally, $2 \mathrm{~mL}$ of $1 \mathrm{M} \mathrm{NaOH}$ was added to the mixture. Immediately, the volume of the mixture was made up to $10 \mathrm{~mL}$ by the addition of $2.4 \mathrm{~mL}$ double distilled water and mixed thoroughly. The absorbance of all samples was measured at a fixed wavelength of $510 \mathrm{~nm}$ using a UV/Visible spectrophotometer (UV professional double beam, Shimadzu made). Quercetin standard was used for the calibration curve. Total flavonoid content was determined as $\mathrm{mg} / \mathrm{g}$ of quercetin equivalent ( $\mathrm{mg}$ of $\mathrm{QE} / \mathrm{g}$ of dry extract) by using the equation obtained from a standard quercetin calibration curve $\mathrm{y}=0.0081 \mathrm{x}, \mathrm{R}^{2}=0.9744$. All the 
determinations were carried out in triplicate and the results were averaged.

\section{Antioxidant activity test}

The free radical scavenging activity was measured by using DPPH (1,1-diphenyl-2-picryl hydrazyl) radical scavenging assay as described by Hossain et al. and Sharma et al. with some modifications [18,21]. Different concentrations $(10,30,50,70,90 \& 110 \mu \mathrm{g} /$ $\mathrm{mL}$ ) of extracts and ascorbic acid (positive control) were prepared. From each solution, $1 \mathrm{~mL}$ of each solution was taken in an Eppendorf tube and $1 \mathrm{~mL}$ of the $0.2 \mathrm{mM}$ DPPH solution was added. The tubes were shaken and allowed to stand at $30{ }^{\circ} \mathrm{C}$ for half an hour. The absorbance was taken on a UV-Visible spectrophotometer (UV professional double beam, Shimadzu made) at $517 \mathrm{~nm}$. Lower the absorbance of the reaction mixture indicates higher free radical scavenging activity. Measurement was performed in triplicate and the percentage radical scavenging activity was calculated using the following equation:

The standard graph of concentration versus the percentage of free radical scavenging activity was plotted. Based on this graph, the $\mathrm{IC}_{50}$ value of each extract was calculated and these values were compared. The $\mathrm{IC}_{50}$ value closest to that of ascorbic acid is considered to have the best antioxidant property [22].

$\%$ radical scavenging activity $=\left(\mathrm{Abs}_{{ }_{\text {control }}}-\mathrm{Abs}_{\text {sample }_{\text {e }}} / \mathrm{Abs}_{\text {control }}\right) \times 100 \%$

\section{Results and Discussion}

\section{Extraction and phytochemical analysis}

The yields of hexane, chloroform, and methanol extracts of the leaves of Ocimum sanctum were 3.5\%, $10.50 \%, 15.25 \%$ respectively. The percentage yield of extract increases with the increase of the polarity of the solvent. The qualitative analysis of the three different extracts (Table 1) showed the presence of different phytochemical constituents. Flavonoids and terpenoids were present in all extracts. Alkaloids, glycosides, polyphenols, tannins, and steroids were present in chloroform and methanol extract. Proteins were found in methanol extract only. The presence of these metabolites in the plant helps to show antioxidant potency and other biological properties [23].
Table 1: Phytochemical screening of different extracts of

\begin{tabular}{lccc}
\multicolumn{4}{c}{ leaves of Ocimum sanctum } \\
\hline \multicolumn{1}{c}{ Phytochemicals } & $\begin{array}{c}\text { Hexane } \\
\text { extract }\end{array}$ & $\begin{array}{c}\text { Chloroform } \\
\text { extract }\end{array}$ & $\begin{array}{c}\text { Methanol } \\
\text { extract }\end{array}$ \\
\hline Alkaloids & - & + & + \\
Flavonoids & + & + & ++ \\
Cardiac glycosides & - & - & - \\
Glycosides & - & + & + \\
Polyphenols & - & + & ++ \\
Terpenoids & + & + & + \\
Steroids & - & + & + \\
Proteins & - & - & + \\
Quinones & + & - & - \\
Tannins & - & + & ++ \\
Reducing sugar & - & - & - \\
\hline
\end{tabular}

Key: $+=$ Present $-=$ Absent

\section{Total phenolic content (TPC) and total flavonoid content (TFC)}

In the present study, the total phenolic and flavonoid contents of three different extracts of Ocimum sanctum were determined. TPC and TFC were calculated by extrapolation from the calibration curve prepared from gallic acid and quercetin concentrations, respectively. Table 2 displays the TPC and TFC of three different extracts of Ocimum sanctum.

Table 2: Total phenolic and total flavonoid contents of different extracts of Ocimum sanctum leaves

Data expressed as mean $\pm \mathrm{SE}$ of three replicates

\begin{tabular}{|c|c|c|}
\hline Extract & $\begin{array}{c}\text { Total phenolic content (mg } \\
\text { GAE/g of dry extract) }\end{array}$ & $\begin{array}{c}\text { Total flavonoid content } \\
\text { (mg QE/g of dry extract) }\end{array}$ \\
\hline Hexane & $60.55 \pm 0.25$ & $16.91 \pm 0.56$ \\
\hline Chloroform & $77.34 \pm 0.76$ & $38.47 \pm 0.23$ \\
\hline Methanol & $180.21 \pm 0.89$ & $67.11 \pm 0.43$ \\
\hline
\end{tabular}

The result showed significant total phenolic and flavonoid content in plant extracts. The number of total phenolic content was determined as quite high in methanol extract of $O$. sanctum (180.21 \pm $0.89 \mathrm{mg} \mathrm{GAE} / \mathrm{g}$ ). It was found that total flavonoid content is also found highest in methanol extract (67.11 $\pm 0.43 \mathrm{mg} \mathrm{QE} / \mathrm{g}$ ) followed by chloroform and hexane extract. The polarity of the solvents may affect the concentration of TPC and TFC. The high concentration of phenolic and flavonoid components in the plant, may effectively eliminate free radicals and they directly contribute as antioxidants $[23,24]$. The sufficient amount of total phenolic and total flavonoid content in $O$. sanctum has been reported by 
several authors also [25-29].

\section{DPPH radical scavenging activity}

DPPH assay was carried out to analyze the antioxidant activity of the plant by using ascorbic acid as standard. In this assay, different concentrations of different extract solutions and ascorbic acid solutions were incubated at room temperature and their absorbance was recorded by spectrophotometer. The percentage of free radical scavenging at different concentrations and $\mathrm{IC}_{50}$ values of each extract and ascorbic acid were calculated and the results are presented in table 3 and figure 1 .

The figure above shows that percentage inhibition of DPPH free radical by extracts of $O$. sanctum was found to be near to ascorbic acid which was taken as standard. $\mathrm{IC}_{50}$ values of three extracts were also found to be close to the standard ascorbic acid taken.
So, methanol extract of $O$. sanctum is more potent in terms of antioxidant activity. It also contains the highest amount of TPC $(180.21 \pm 0.89 \mathrm{mg} \mathrm{GAE} / \mathrm{g}$ of dry extract) and TFC $(67.11 \pm 0.43 \mathrm{mg}$ QE/g of dry extract). The high antioxidant activity of the methanol extract may be due to the presence of phytochemicals such as flavonoids, polyphenols, and tannins. This work is also supported by previous reports that flavonoids, polyphenols, and tannins found in plants have significant antioxidant activity $[25,26]$. This shows that $O$. sanctum leaves can act as a very good option in the field of medicine based on the antioxidant property of natural products chemistry. Previous studies from various researchers reported $O$. Sanctum as a protective antioxidant supplement $[30,32]$. Kelm et al. isolated six major compounds from $O$. sanctum which are responsible for exhibiting antioxidant activity by the plant [32].

Table 3: $D P P H$ free radical scavenging activity and $I C_{50}$ values of $O$. sanctum extracts and standards

\begin{tabular}{|l|l|l|l|l|}
\hline \multirow{2}{*}{$\begin{array}{l}\text { Concentration } \\
(\boldsymbol{\mu g} / \mathbf{m L})\end{array}$} & \multicolumn{3}{|c|}{ \% free radical scavenging activity } \\
\cline { 2 - 5 } & Hexane extract & Chloroform extract & Methanol extract & Ascorbic acid \\
\hline 0 & 0 & 0 & 0 & 0 \\
\hline 10 & 5.71 & 24.28 & 44.28 & 48.57 \\
\hline 30 & 18.57 & 31.42 & 52.85 & 57.14 \\
\hline 50 & 30.0 & 42.85 & 60.0 & 62.85 \\
\hline 70 & 40.0 & 50.0 & 65.71 & 67.14 \\
\hline 90 & 48.57 & 54.28 & 68.57 & 74.28 \\
\hline 110 & 54.0 & 57.14 & 71.42 & 77.14 \\
\hline $\mathbf{I C}_{\mathbf{5 0}}$ value $(\boldsymbol{\mu g} / \mathbf{m L})$ & 95.68 & 79.46 & 47.73 & 41.34 \\
\hline
\end{tabular}

Values are expressed as mean $\pm \operatorname{SD}(n=3)$

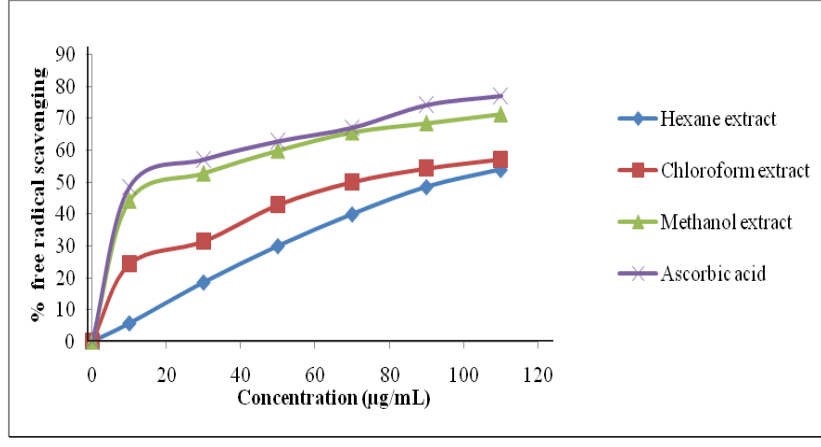

Figure 1: Comparison of \% radical scavenging between ascorbic acid and different extracts of $O$. sanctum

Among the three different extracts, methanol extract was found to have the $\mathrm{IC}_{50}$ value of $47.73 \mu \mathrm{g} / \mathrm{mL}$, very close to standard ascorbic acid $(41.34 \mu \mathrm{g} / \mathrm{mL})$.

\section{Conclusion}

In the present investigation, extractions from Ocimum sanctum leaves powder has been carried in hexane, chloroform and methanol solvents. Phytochemical screening of the extracts revealed the presence of alkaloids, flavonoids, tannins, glycosides, polyphenols, terpenoids, tannins and steroids. The plant possesses a high amount of total phenolic and total flavonoid contents. DPPH scavenging activity showed that the plant possesses high antioxidant properties. Among all three extracts, the $\mathrm{IC}_{50}$ value of methanol extract was the lowest and closest (47.73 $\mu \mathrm{g} / \mathrm{mL})$ to that of standard ascorbic acid $(41.34 \mu \mathrm{g} /$ $\mathrm{mL}$ ). The significant potency of the extracts of $O$. 
sanctum leaves as antioxidant agents may be due to the presence of high phenolic and flavonoid contents.

\section{Acknowledgements}

The authors are thankful to the Department of Chemistry, Amrit Campus, Tribhuvan University and Department of Forest and Soil Conservation, Babarmahal, Kathmandu for providing the laboratory facility.

\section{References}

1. K. Selvam, R. Rajinikanth, M. Govarthanan, A. Paul, T. Selvankumar and A. Sengottaiyan, Antioxidant potential and secondary metabolites in Ocimum sanctum L. at various habitats, Journal of Medicinal Plants Research, 2013, 7(12), 706-712. (DOI: 10.5897/JMPR11.446).

2. S. I. Vidhani, V. G. Vyas, H. J. Parmar, V. M. Bhalani, M. M. Hossan, A. Gaber and B. A. Golakiya, Evaluation of some chemical composition, minerals fatty acid profiles, antioxidant and antimicrobial activities of Tulsi (Ocimum sanctum) from India, American Journal of Food Science and Technology, 2016, 4(2), 52-57. (DOI: 10.12691/ ajfst-4-2-5).

3. B. Joshi, G. P. Sah, B. B. Basnet, M. R. Bhatt, D. Sharma, K. Subedi, J. Pandey and R. Malla, Phytochemical extraction and antimicrobial properties of different medicinal plants: Ocimum sanctum (Tulsi), Eugenia caryophyllata (Clove), Achyranthes bidentata (Datiwan) and Azadirachta indica (Neem), Journal of Microbiology and Antimicrobials, 2011, 3(1), 1-7.

4. G. Nahak, R. C. Mishra and R. K. Sahu, Phytochemical investigation and in vitro antioxidant evaluation of some Ocimum species, Journal of Pharmacy Research, 2011, 4(7), 23402343.

5. P. Prakash and N. Gupta, Therapeutic uses of Ocimum sanctum Linn (Tulsi) with a note on eugenol and its pharmacological actions: a short review, Indian Journal of Physiology and Pharmacology, 2005, 49(2), 125-131.

6. M. K. Khosla, Sacred tulsi (Ocimum sanctum) in traditional medicine and pharmacology, Ancient Science of Life, 1995, 5(1), 53-61.
7. M. M. Cohen, Tulsi-Ocimum sanctum: A herb for all reasons, Journal of Ayurveda Integrative Medicine, 2014, 5(4), 251-259.

8. V. Gradinariu, O. Cioanca, L. Hritcu, A. Trifan, E. Gille and M. Hancianu, Comparative efficacy of Ocimum sanctum L. and Ocimum basilicum $L$. essential oils against amyloid beta (1-42)-induced anxiety and depression in laboratory rats, Phytochemistry, 2015, 14(4), 567-575.

9. P. Pattanayak, P. Behera, D. Das and S. K. Panda, Ocimum sanctum Linn. A reservoir plant for therapeutic applications: An overview, Pharmacognosy Reviews, 2010, 4(7), 95-105. (DOI: 10.4103/0973-7847.65323).

10. B. Joseph and V. M. Nair, Ethanopharmacological and phytochemical aspects of Ocimum sanctum Linn-The Elixir of Life, British Journal Pharmaceutical Research, 2013, 3(2), 273-292.

11. S. E. Lee, H. J. Hwang, J.-S. Ha, H.-S. Jeong and J. H. Kim, Screening of medicinal plant extracts for antioxidant activity, Life Sciences, 2003, 73(2), 167-179.

12. A. J. Harborne, Phytochemical methods a guide to modern techniques of plant analysis, Springer Science \& Business Media, UK, 1998.

13. B. Subba, A. Sharma and A. Budhathoki, Assessment of phytochemical content, antioxidant and antibacterial activities of three medicinal plants of Nepal, Journal of Medicinal Plants Research, 2016, 10(45), 829-837. (DOI:10.5897/ JMPR2016.6269).

14. F. L. Hakkim, G. Arivazhagan and R. Boopathy, Antioxidant property of selected Ocimum species and their secondary metabolite content, Journal of Medicinal Plants Research, 2008, 2(9), 250-257.

15. D. Gajula, M. Verghese, J. Boateng, L. T. Walker, L. Shackefold, S. R. Mentreddy and S. Cedric, Determination of total phenolics, flavonoids and antioxidant and chemopreventive potential of basil (Ocimum basilicum L. and Ocimum tenuiflorum L.), International Journal of Cancer Research, 2009, 5(4), 130-143, (DOI: 10.3923/ijcr.2009.130.143).

16. H. Hossain, I. A. Jahan, H. S. Islam, D. S. Kanti, H. Arpona and A. Arif, Phytochemical screening and anti-nociceptive properties of the ethanolic 
leaf extract of Trema Cannabina Lour, Advanced Pharmaceutical Bulletin, 2013, 3(1), 103-108. (http://dx.doi.org/10.5681/apb.2013.017).

17. M. A. Hossain, K. A. S. AL-Raqmi, Z. H. ALMijizy, A. M. Weli and Q. Al-Riyami, Study of total phenol, flavonoids contents and phytochemical screening of various leaves crude extracts of locally grown Thymus vulgaris, Asian Pacific Journal of Tropical Biomedicine, 2013, 3(9), 705-710. (DOI: 10.1016/S2221-1691(13)60142-2).

18. M. A. Hossain, M. D. Shah, C. Gnanaraj and M. Iqbal, In vitro total phenolics, flavonoids contents and antioxidant activity of essential oil, various organic extracts from the leaves of tropical medicinal plant Tetrastigma from Sabah, Asian Pacific Journal of Tropical Medicine, 2011, 4(9), 717-721.

19. S. Sankhalkar and V. Vernekar, Quantitative and qualitative analysis of phenolic and flavonoid content in Moringa oleifera Lam and Ocimum tenuiflorum L., Pharmacognosy Research, 2016, 8(1), 16-21. (DOI: 10.4103/0974-8490.171095).

20. S. Chandra, S. Khan, B. Avula, H. Lata, M. H. Yang, M. A. Elsohly and I. A. Khan, Assessment of total phenolic and flavonoid content, antioxidant properties, and yield of aeroponically and conventionally grown leafy vegetables and fruit crops: A comparative study, Evidenced Based Complementary and Alternative Medicine, 2014, 14, 1-9. (DOI.org/10.1155/2014/253875).

21. K. R. Sharma, S. K. Kalauni and S. Awale, Antioxidant, phytotoxic and antimicrobial activities of methanolic extract of Bauhinia variegata barks, Journal of Institute of Science and Technology, 2015, 20(2), 37-41.

22. N. A. Khalaf, A. K. Shakya, A. Al-Othman, Z. ElAgbar and H. Farah, Antioxidant activity of some common plants, Turkish Journal of Biology, 2008, 32(1), 51-55.

23. C. A. Rice-Evans, N. J. Miller and G. Paganga, Structure-antioxidant activity relationships of flavonoids and phenolic acids, Free Radical Biology and Medicine, 1996, 20(7), 933-956.

24. E. J. Lien, S. Ren, H.-H. Bui and R. Wang, Quantitative structure-activity relationship analysis of phenolic antioxidants, Free Radical Biology and
Medicine, 1999, 26(3), 285-294. (DOI:285-294. 10.1016/S0891-5849(98)00190-7).

25. S. Kaur, Study of total phenolic and flavonoid content, antioxidant activity and antimicrobial properties of medicinal plants, Journal of Microbiology and Experimentation, 2014, 1(1), 1-6.

26. S. Guleria, A. K. Tiku, G. Singh, A. Koul, S. Gupta and S. Rana, In-vitro antioxidant activity and phenolic contents in methanol extracts from medicinal plants, Journal of Plant Biochemistry and Biotechnology, 2013, 2(1), 9-15. (DOI: 10.1007/s13562-012-0105-6).

27. B. Piyali, M. Poiyandarshini, M. Sayan and V. A. Swarup, Assessment of antioxidant, anti-inflammatory, anti-cholinesterase and cytotoxic activities of Tulsi leaves, Advances in Pharmacology and Toxicology, 2014, 15(1), 1929.

28. A. Bhattacharya, A. Agarwal, N. Sharma and J. Cheema, Evaluation of anti-oxidative constituents of three species of Ocimum, International Journal of Life Sciences, 2014, 8(5), 14-17. (DOI: dx.doi. org/10.3126/ijls.v8i5.11858).

29. J. V. Vastrad, G. Goudav, S. A. Byadgi, R. D. Devi and R. Kotur, Identification of bioactive components in leaf extracts of Aloe-vera and tulasi, Journal of Medicinal Plants Research, 2015, 9(28), 764-770.

30. E. Mitra, D. Ghosh, A. K. Ghosh, A. Basu and D. Bandyopadhay, Aqueous Tulsi leaf (Ocimum sanctum) extract possesses antioxidant properties and protects against Cadmium-induced oxidative stress in rat heart, Journal of Pharmacy and Pharmaceutical Science, 2014, 6(1), 500-513.

31. J. Samson, R. Sheeladevi and R. Ravinandan, Oxidative stress in brain and antioxidant activity of Ocimum sanctum in noise exposure, Neuro Toxicology, 2007, 28, 679-685.

32. M. A. Kelm, M. G. Nair, G. M. Strasburg and D. L. Dewitt, Antioxidant and cyclooxygenase inhibitory phenolic compounds from Ocimum sanctum Linn., Phytomedicine, 2000, 7(1), 7-13. 